\title{
PARTILHANDO METAS COMUNS EM SAÚDE E DIREITOS DA CRIANÇA: UM ENCONTRO DE PROJETOS DE EXTENSÃO
}

\author{
SHARING COMMON GOALS IN CHILD HEALTH AND RIGHTS: \\ AN ENCOUNTER OF EXTENSION PROJECTS
}

Douver Michelon

Ruth Irmgard Bärtschi Gabatz

Ananda Rosa Borges ${ }^{3}$

Vanessa Polina Pereira Costa ${ }^{4}$

Catiara Terra da Costa ${ }^{5}$

Marcos Antônio Pacce ${ }^{6}$

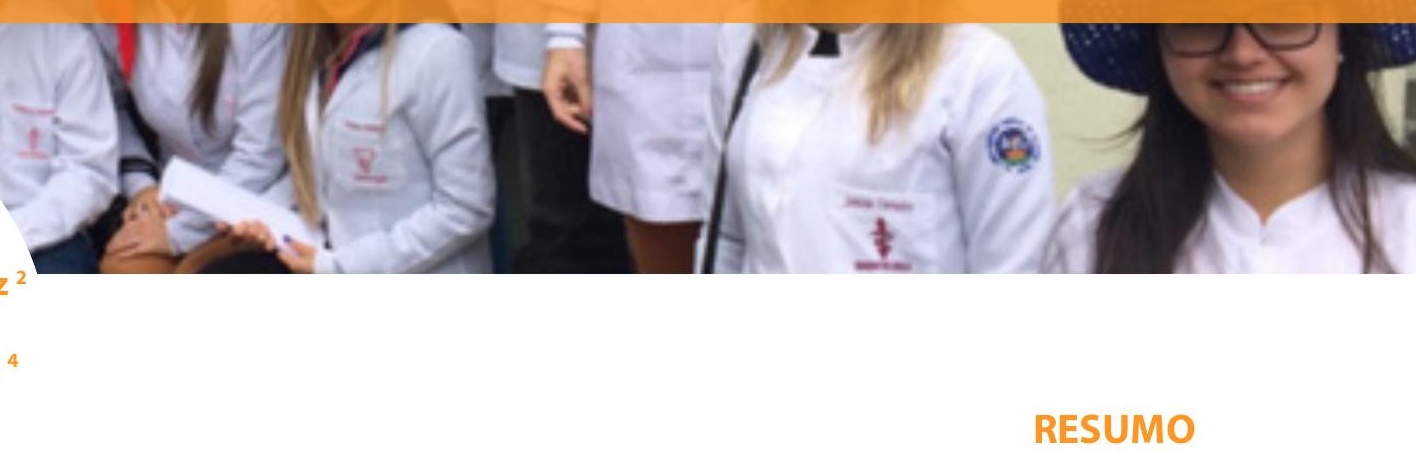

Os Direitos Humanos são direitos fundamentais dos indivíduos, independentemente de raça, sexo, idade ou nacionalidade. Entre as crianças e os adolescentes os Direitos Humanos não significam apenas a indicação de um grupo etário específico dentre os sujeitos titulares desses direitos, mas, sobretudo, o reconhecimento de um status especial atribuído aos direitos fundamentais que possuem, dentre eles o direito à saúde. Sendo esse tema específico muito sensível e caro para a sociedade, esse trabalho tem por objetivo realizar uma apresentação breve da trajetória das conquistas relacionadas aos direitos e à saúde na infância na sociedade brasileira, bem como ressaltar a relevância de iniciativas em extensão universitária nesse contexto, especialmente aquelas que levam às ações integradas em projetos na área da saúde. No Brasil, enquanto política legislativa, foi somente nos anos 70 que o público infantil começou a ganhar especificidade. Desse período em diante, um processo de avanço continuado vem ocorrendo. Nesse sentido, as iniciativas públicas para o apoio às ações de extensão nas Instituições de Ensino Superior (IES) têm sido decisivas para a consolidação dos direitos da criança, especialmente na área da saúde. Os protagonistas da extensão universitária podem encontrar vantagens significativas na integração de práticas e no partilhamento de experiências. Assim, é de extrema importância que as equi-

\footnotetext{
${ }^{1}$ Doutor em Ortodontia. Professor Adjunto de Ortodontia - Departamento de Odontologia Social e PreventivaFaculdade de Odontologia - Universidade Federal de Pelotas. E-mail: douvermichelon@gmail.com

${ }^{2}$ Enfermeira, Doutora em Ciências da Saúde. Professora Adjunta da Faculdade de Enfermagem da Universidade Federal de Pelotas. E-mail: r.gabatz@yahoo.com.br

${ }^{3}$ Acadêmica do Curso de Bacharelado em Enfermagem da Faculdade de Enfermagem, Universidade Federal de Pelotas. E-mail: nandah_rborges@ @otmail.com
} 
pes de diferentes projetos em saúde busquem associar metas e alinhar diretrizes políticas abordadas, promovendo, assim, de uma forma mais ampla a saúde e a qualidade de vida das crianças e suas famílias.

Palavras chave: Direitos Humanos. Saúde da Criança. Serviços de Saúde em Universidades.

\section{ABSTRACT}

Human Rights are fundamental rights of individuals, regardless of race, sex, age or nationality. Among children and adolescents, Human Rights do not only mean the indication of a specific age group among the subjects who hold these rights, but also the recognition of a special status attributed to the fundamental rights they possess, among them the right to health. Since this specific theme is very sensitive and dear to society, this work aims to make a brief presentation of the trajectory of achievements related to rights and health in childhood in Brazilian society, as well as highlighting the relevance of initiatives in university extension in this context, especially those that lead to integrated actions in health projects. In Brazil, as a legislative policy, it was not until the 1970s that the children's public began to gain specificity. From this period onwards, a process of continuous advancement has been occurring. In this sense, public initiatives to support extension actions in Higher Education Institutions (HEls) have been decisive for the consolidation of children's rights, especially in the area of health. The protagonists of university extension can find significant advantages in the integration of practices and the sharing of experiences. Thus, it is extremely important that the teams of different health projects seek to associate goals and align policy guidelines, thus promoting in a broader way the health and quality of life of children and their families.

Keywords: Human Rights. Child health. University Health Services.

\section{INTRODUÇÃO}

Os direitos humanos são os direitos fundamentais, enunciados historicamente a partir do reconhecimento materializado nas legislações e com base na inerente dignidade de todo indivíduo, independentemente de

\footnotetext{
${ }^{4}$ Doutora em Odontopediatria. Professora Adjunta de Odontopediatria - Departamento de Odontologia da Faculdade de Ciências da Saúde - Universidade de Brasília - UnB. E-mail: polinatur@yahoo.com.br ${ }^{5}$ Doutora em Odontopediatria. Especialista em Ortodontia e Ortopedia Facial dos Maxilares.

Professora Adjunta de Ortodontia na Faculdade de Odontologia - Universidade Federal de Pelotas. E-mail: catiaraorto@gmail.com

${ }^{6}$ Doutor em Odontopediatria. Especialista em Ortodontia e Ortopedia Facial dos Maxilares. Professor Adjunto de Ortodontia - Faculdade de Odontologia- Universidade Federal de Pelotas. E-mail:semcab @ gmail.com
} 
raça, sexo, idade ou nacionalidade. A consagração desses direitos constitui um traço marcante do processo civilizatório, e a sua efetiva implementação um indicador seguro do nível de desenvolvimento humano atingido por um povo ou nação.

A expressão "direitos humanos de crianças e adolescentes" não significa, apenas, a indicação de um grupo etário específico dentre os sujeitos titulares desses direitos. Ela remete ao reconhecimento de um status especial atribuído aos direitos fundamentais que possuam por titulares crianças e adolescentes, elegidos como sendo merecedores de distinta proteção. De fato, às crianças e adolescentes são conferidos, além de todos os direitos fundamentais consagrados a qualquer pessoa humana, outros direitos igualmente fundamentais, mas que Ihes são específicos, tais como o direito à inimputabilidade penal e o direito à convivência familiar e comunitária.

Além disso, todos os direitos fundamentais de que gozam as crianças e adolescentes são alcançados pelo princípio da prioridade, segundo o qual sua proteção e satisfação devem ser buscados e assegurados pelo Estado, antes de quaisquer outros. Ou seja, dentre os direitos fundamentais reconhecidos a todos os indivíduos, expressão de sua intrínseca dignidade, aqueles relativos à crianças e adolescentes hão de vir em primeiro lugar.

\footnotetext{
É dever da família, da sociedade e do Estado assegurarà criança e ao adolescente, com absoluta prioridade, o direito à vida, à saúde, à alimentação, à educação, ao lazer, à profissionalização, à cultura, à dignidade, ao respeito, à liberdade e à convivência familiar e comunitária, além de colocá-los a salvo de toda forma de negligência, discriminação, exploração, violência, crueldade e opressão (MINISTÉRIO PÚBLICO, 2017).
}

O Brasil foi um dos primeiros países a adequar a legislação interna aos princípios consagrados pela Convenção das Nações Unidas, expressando a necessidade de mudanças na sociedade em seus aspectos culturais, buscando combater práticas de segregação e discriminação impostas aos menores em situação de abandono ou vulnerabilidade.

Enquanto política legislativa, o Estatuto da Criança e do Adolescente representa um grande avanço na promoção de direitos da população em desenvolvimento (SANTOS et al., 2017). No entanto, o processo de efetivação dos direitos da criança e do adolescente se deu em um contexto histórico bem mais amplo que o ato de legislar. Na realidade atual, esse processo ainda está em andamento, e sua realização plena requer ainda um grande número de conquistas no campo teórico e prático. Nesse cenário, as ações de extensão universitária constituem uma parcela importante dos esforços dirigidos no sentido de consolidar e ampliar o acesso aos direitos e a saúde no Brasil. 


\section{A LEGISLAÇÃO E OS DIREITOS DA CRIANÇA E DO ADOLESCENTE}

De acordo com Schuch (2006) a constituição dos direitos das pessoas não está relacionada apenas a regras, processos, rituais e procedimentos judiciários, mas diz respeito também as "formas de pensamento ou maneiras de imaginar a realidade, que revestem de significado a multiplicidade de práticas, saberes e dispositivos empregados". Neste contexto, a elaboração dos direitos é constituída de diversos significados, que englobam cidadania, justiça e democracia.

Os processos de elaboração de políticas para atenção à infância e juventude surgem de embates ideológicos muito mais do que valores humanitários instituídos, sendo que a população diretamente envolvida (crianças e adolescentes), muitas vezes não é questionada quanto apercepção acerca dos seus direitos. Contudo, para melhor compreensão de como se desenvolveu a constituição dos direitos das crianças e adolescentes, considera-se importante uma revisão acerca das políticas e leis desenvolvidas ao longo dos anos.

Na década de 1920 surge a ideia de uma legislação para menores no Brasil com o primeiro Código de Menores, no entanto neste não existe distinção entre infância e adolescência (RIZZINI, 2011). No dia 11 de dezembro de 1946 foi criado, na Assembleia Geral das Nações Unidas, a Fundação das Nações Unidas para a Infância (UNICEF), o que contribuiu para o crescimento da ideia de um indivíduo com direitos fundamentais específicos ou especiais. No Brasil, o primeiro escritório da UNICEF foi instalado em 1950 (UNICEF, 2017).

Em 1959, foi feita a Declaração Universal dos Direitos das Crianças, portanto à partir de 1960 passa a ocorrer uma alteração significativa no modelo de assistência à infância no Brasil (MARCíLIO, 2010). Nessa declaração, as crianças teriam assegurados direitos à igualdade, à proteção para o seu desenvolvimento físico, mental e social, a um nome, uma nacionalidade, à alimentação, à moradia, à assistência médica, à educação e a cuidados especiais, para os casos de crianças física ou mentalmente deficientes, ao amor, à compreensão por parte dos pais e da sociedade, à educação gratuita, ao lazer infantil, à socorro em primeiro lugar no caso de catástrofes, à ser protegida contra o abandono e exploração no trabalho e à crescer dentro de um espírito de solidariedade, compreensão, amizade e justiça entre os povos (UNICEF, 2017).

No ano de 1978, foi realizada na data de 6 a 12 de setembro a Conferência Internacional sobre Cuidados Primários de Saúde, na qual foi formulada a Declaração de Alma-Ata. Nessa declaração é enfatizado que a saúde é um direito humano fundamental e que os cuidados primários de saúde são cuidados essenciais de saúde. A Declaração de Alma-Ata assumiu com meta atingir níveis aceitáveis de saúde para todos os povos até 
o ano de 2000 (DECLARAÇÃO ALMA-ATA, 1978).Em 1979, é elaborado um novo Código de Menores, alterando o que é uma das primeiras estruturas de proteção aos menores no Brasil. Nessa alteração alguns termos utilizados para determinar as crianças em risco foram revistos (RIZZINI; RIZZINI, 2004). Neste mesmo ano foi proclamado, pela ONU e UNICEF, o Ano Internacional da Criança, quando foram organizados diversos eventos que debateram questões relacionadas à infância, como a noção de "crianças do mundo" (VIANNA, 2002).

Em 19 de setembro de 1990, foi criada a Lei № 8.080 que "dispõe sobre as condições para promoção, proteção e recuperação da saúde, a organização e o funcionamento dos serviços correspondentes e dá outras providências". O artigo segundo da legislação diz que o Estado é quem tem o dever de prover condições indispensáveis ao seu pleno exercício (BRASIL, 1990).

Em 13 de julho de 1990, foi criada a Lei № 8.069 que "dispõe sobre o Estatuto da Criança e do Adolescente e dá outras providências. Em 8 de março de 2016 a Lei № 13.257 altera a Lei № 8.069 (BRASIL, 2016). O Estatuto da Criança e do Adolescente estabelece que as crianças e os adolescentes devem ter assegurados todos os direitos fundamentais inerentes à pessoa humana, e todas as oportunidades e facilidades para o desenvolvimento físico, mental, moral, espiritual e social. Também deve ser assegurado o acesso integral às linhas de cuidado da saúde da criança e do adolescente, fazendo com que os profissionais atuantes no cuidado desta parcela da população recebam formação específica e permanente (BRASIL, 2016).

Em 12 de outubro de 1991, foi criada a Lei № 8.242 que "cria o Conselho Nacional dos Direitos da Criança e do Adolescente (CONANDA) e dá outras providências" (BRASIL, 1991). Em 5 de dezembro de 2007, foi criado o Decreto № 6.286 que "institui o Programa Saúde na Escola (PSE) e dá outras providencias" (BRASIL, 2007). O Programa Saúde na Escola possui como objetivos principais:

I - promover a saúde e a cultura da paz, reforçando a prevenção de agravos à saúde, bem como fortalecer a relação entre as redes públicas de saúde e de educação; II - articular as ações do Sistema Único de Saúde - SUS às ações das redes de educação básica pública, de forma a ampliar o alcance e o impacto de suas ações relativas aos estudantes e suas famílias, otimizando a utilização dos espaços, equipamentos e recursos disponíveis; III - contribuir para a constituição de condições para a formação integral de educandos; IV - contribuir para a construção de sistema de atenção social, com foco na promoção da cidadania e nos direitos humanos; $\mathrm{V}$ - fortalecer o enfrentamento das vulnerabilidades, no campo da saúde, que possam comprometer o pleno desenvolvimento escolar; VI - promover a comunicação entre escolas e unidades de saúde, assegurando a troca de informações sobre as condições de saúde dos estudantes; e VII - fortalecer a participação comunitária nas políticas de educação básica e saúde, nos três níveis de governo (BRASIL, 2007). 
O PSE também institui que é de responsabilidade das Equipes de Saúde da Família realizar visitas às escolas, com o intuito de avaliar as condições de saúde dos alunos e proporcionar atendimento de saúde de acordo com suas necessidades (BRASIL, 2007).

\section{SAÚDE DA CRIANÇA E POLÍTICAS PÚBLICAS NO BRASIL}

O direito à saúde ganhou avanços importantes no Brasil nas últimas décadas do século XX. A 3a Conferência Nacional de Saúde nos anos 60 definiu o direito de todos à saúde, e a municipalização foi escolhida como caminho para sua implantação (FUNDAÇÃO OSWALDO CRUZ, 2003). Nos anos 70 o público infantil começou a ganhar alguma especificidade, pois nesse período o governo federal se empenhou em elaborar e sustentar programas de atenção à saúde da criança (FIGUEIREDO; MELLO, 2007). Entretanto, somente mais tarde, nos anos 80, ocorreu uma efetivação mais significativa de políticas públicas nesse sentido, com a proposição do Programa Assistência Integral à Saúde da Criança (PAISC), o qual, como o próprio nome diz, toma como base a meta de assegurar a assistência integral à saúde da criança através das ações básicas. Esse programa tomou como referencia os agravos mais frequentes, e com maior impacto na mortalidade de crianças de 0 a 5 anos de idade (MINISTÉRIO DA SAÚDE, 1984). Posteriormente, o desenvolvimento do Programa de Saúde da Família (PSF), criado nos anos 90 pelo Ministério da Saúde, e que teve como objetivo reorientar a atenção básica em saúde assumindo a implementação de atenção à saúde da família como estratégia para efetivação de políticas públicas, assumiu um papel complementar em relação aos direitos da criança.

O PSF toma como base os princípios da universalidade, equidade e integralidade da assistência à saúde (MINISTÉRIO DA SAÚDE, 1998). Esse programa vem sendo visto como um campo propício à incorporação da estratégia Atenção Integrada às Doenças Prevalentes na Infância (AIDPI) (FIGUEIREDO; MELLO, 2007). A AIDPI, por sua vez é uma estratégia adotada no Brasil em 1996, por efeito da proposição feita pela Organização Mundial da Saúde e Fundo das Nações Unidas para a Infância, com o objetivo de promover a redução da mortalidade, e a garantia da adequada qualidade da atenção à saúde de crianças menores de 5 anos, tanto nos serviços de saúde como no domicílio e comunidade. Essa estratégia visa ainda o fortalecimento da promoção à saúde e de ações preventivas na infância (ORGANIZAÇÃO PAN-AMERICANA DA SAÚDE; ORGANIZAÇÃO MUNDIAL DA SAÚDE, 2000; FIGUEIREDO, MELLO, 2007).

A fim de proporcionar a garantia de direitos da população infantil, - Ministério da Saúde lançou também o Caderno de Atenção Básica Saúde da Criança (MINISTÉRIO DA SAÚDE, 2002), que passou a ser 
um instrumento voltado ao acompanhamento sistemático do crescimento e desenvolvimento infantil, para assim funcionar como uma orientação normativa na adoção de medidas para o crescimento e desenvolvimento saudáveis. Essas medidas integram os fundamentos das estratégias da AIDPI (FIGUEIREDO, MELLO, 2007), e foram gradativamente incorporadas às atividades do PSF e do Programa de Agentes Comunitários de Saúde (PACS), uma ação programática que também se refletiu sobre a saúde da criança (MINISTÉRIO DA SAÚDE, 2002).

O Ministério da Saúde lançou mais tarde, em 2004, a Agenda de Compromissos para a Saúde Integral da Criança e Redução da Mortalidade Infantil (MINISTÉRIO DA SAÚDE, 2004). Nesse documento, os cuidados com a saúde infantil integram as ações essenciais do Ministério da Saúde, enfatizando o cuidado integral e multiprofissional baseado na compreensão das necessidades e direitos da criança como indivíduo. Esse documento enfatiza também a responsabilidade de disponibilizar assistência à saúde qualificada e humanizada (FIGUEIREDO; MELLO, 2007).

De modo geral, nas políticas públicas dirigidas a saúde na infância, diversos fatores são colocados como condições que exigem vigilância à saúde, estando estes quase sempre fortemente baseados atualmente no acompanhamento sistemático do crescimento da criança, bem como na identificação dos fatores de risco tanto do ponto de vista orgânico como nos aspectos relacionais à família (FIGUEIREDO; MELLO, 2007).

Outro ponto que precisa ser considerado é o reflexo dos avanços científicos e tecnológicos, os quais proporcionaram também um melhor entendimento dos diferenciais de saúde/doença na população infantil, atuando como fundamento para o avanço das investigações científicas na sociedade (FIGUEIREDO; MELLO, 2007). Estudos na área de saúde materno-infantil têm esclarecido grandemente as associações entre saúde/ doença, renda, saneamento, nutrição, qualidade e quantidade de assistência médica, entre outros temas críticos e diferenciais para a saúde infantil (MONTEIRO; FREITAS, 2002). Assim, é possível aceitar que os avanços no conhecimento técnico e científico podem também exercer influência significativa ou decisiva sobre a concepção e o andamento de políticas públicas voltadas para a saúde da criança.

Os aspectos políticos, sociais e científicos estão, portanto, em grande medida correlacionados entre si quando da aplicação dos conhecimentos nos cuidados à criança, tendo como orientação os fundamentos lançados na Convenção sobre os Direitos da Criança de 1989 (UNICEF,1990).

A garantia de acesso e de atenção qualificada e integral à saúde, de cuidados preventivos e tratamentos postulados nos programas de saúde, tem efeito significativo nas ações de saúde pública sobre direitos humanos. A criança tem direitos que se referem, principalmente, à autonomia pública, ou seja, aos direitos sociais tais como direito ao adequado crescimento e desenvolvimento, a leitamento materno, nutrição, vacinação, higiene, 
saneamento ambiental, medidas de proteção, prevenção de acidentes, acesso à educação, cuidados à saúde, enfim, direito à vida. Aliado a esses aspectos, também é considerado importante a garantia de que os pais conheçam os princípios básicos de saúde, recebendo apoio continuado para aplicação dos conhecimentos no cuidado à criança (FIGUEIREDO; MELLO, 2007). Todas essas práticas são referenciadas como os elementos essenciais para proporcionar boas condições de saúde na infância (VICTORAet al., 2011; UNICEF, 2011).

O entendimento do processo saúde-doença e os modelos de cuidado em saúde implicam em experiências singulares e intersubjetivas, sendo relevante tematizar o encontro e a interação entre os sujeitos, enfatizando as particularidades de cada família, as relações interpessoais e a organização da assistência, buscando assim contribuir para a reconstrução das práticas de saúde (MELLO et al., 2012).

\section{A ARTICULAÇÃO DE PROJETOS COMO ESTRATÉGIA DE QUALIFICAÇÃO EM EXTENSÃO}

Atualmente, muitas questões relacionadas à saúde da criança no mundo todo estão associadas à vulnerabilidade social e a questões dos direitos humanos não compreendidas ou não atendidas por instituições públicas. No Brasil as diretrizes políticas relacionadas à saúde infantil têm proporcionado avanços significativos, bem como oportunizado diversas ações concretas dirigidas à população infantil. Nesse sentido, as iniciativas institucionais de apoio às ações de Extensão nas IES, ou aquelas originadas em programas governamentais, como é o caso dos editais ProExt lançados pelo Ministério da Educação e Cultura até 2015, têm desempenhado um importante papel na efetivação concreta dos direitos da criança.

As ações programáticas em Extensão, tanto implementadas por IES e como pelo Estado, apoiam importantes práticas de humanização e de fortalecimento do papel da universidade junto às comunidades que as cercam. Sobretudo, essas ações suscitam o meio acadêmico a promover discussões e reflexões importantes sobre as necessidades de saúde nas comunidades, sobre vulnerabilidades, cidadania e direitos humanos. Essas reflexões por sua vez têm instigando a revisão de modelos preexistentes, e incentivando a busca por soluções de problemas que sejam mais eficientes e abrangentes.

Muitas discussões sobre as questões vinculadas ao papel da Universidade na assistência primária à saúde, particularmente aquelas relativas à prioridade dos serviços de saúde e necessidades de assistência promotora e preventiva voltadas para a saúde da criança, proporcionam o confronto com grandes desafios de ordem operacional, e relacio- 
nados a racionalização de recursos humanos e financeiros. Na prática, muitas barreiras ligadas a essas necessidades precisam ser superadas para que metas em extensão sejam realmente atingidas. Assim, o encontro de interesses comuns e o partilhamento de recursos entre projetos de Extensão Universitária, podem certamente contribuir para a ampliação dos seus públicos, para o aumento do alcance de metas e objetivos, e principalmente para a qualificação da experiência acadêmica envolvida no processo.

Nesse sentido o projeto O Projeto de Extensão Aprender/Ensinar Saúde Brincando, coordenado pela profa. Dra. Ruth Irmgard Bärtschi Gabatz do curso de Enfermagem, e o Programa de Extensão Crescendo com um Sorriso - Núcleo de Atenção às Disfunções Orofaciais na Criança, coordenado pelo prof. Dr. Douver Michelon do curso de Odontologia, ambos institucionalizados na Universidade Federal de Pelotas (UFPel), ao longo dos seus respectivos desenvolvimentos encontraram metas e parcerias em comum, entre outras similaridades. Essas características em comum proporcionaram uma aproximação natural entre duas áreas da saúde durante suas atuações junto à comunidade local. Os docentes e discentes extensionistas perceberam rapidamente as vantagens das ações associativas, do partilhamento de experiências, e sobretudo, do entendimento de que parcerias multiprofissionais podem contribuir muito para promover o enriquecimento e a qualificação de recursos humanos, fatores esses decisivos para o desenvolvimento de ações realizadas em ambos os projetos com maiores benefício para a comunidade.

Alunos e professores puderam encontrar nessas iniciativas muitas oportunidades de crescimento e aprendizado. A troca de experiências exitosas, o aperfeiçoamento de metodologias e a integração de ações foi percebida como importante fator de crescimento para ambos os grupos. Além disso, tiveram a oportunidade de reavaliar os usos dos seus recursos com vistas a um melhor enfrentamento, especialmente em ambientes de grandes demandas relativas à saúde da criança, como é o caso da rede pública de saúde. Sobretudo, os integrantes das duas equipes inauguraram juntos um repensar o seu fazer em extensão, atingindo uma dimensão cultural mais ampla e abrangente.

O espírito colaborativo e o intercâmbio entre as equipes tiveram também efeitos ético e moral positivos e importantes sobre os membros das equipes, uma vez que uma reflexão sistematizada de suas práticas em extensão foi capaz de criar melhores condições para a construção continuada sobre o bem maior em saúde da comunidade. Além disso, foi percebido que o trabalho em equipes plurais, teve um notório efeito de aumento da motivação entre os membros das equipes. Analogias podem ser feitas considerando ganhos equivalentes encontrados nas parcerias entre conhecimento acadêmico e popular, entre as práticas de ensino, pesquisa e extensão ou ainda nos benefícios das relação acadêmicas entre alunos 
e professores. Sobretudo, o crescimento de parcerias de trabalho colocam em destaque o papel das instituições acadêmicas na luta pela transformação social, ao mesmo tempo que contribuem para formação ética e humanística de seus docentes e discentes.

\section{O PROJETO DE EXTENSÃO APRENDER/ENSINAR SAÚDE BRINCANDO}

O brincar é uma forma de conquistar confiança e ensinar às crianças formas de autocuidado, como uma boa higiene, alimentação saudável, vacinação e cuidados relacionados a práticas do cotidiano infantil, favorecendo a participação efetiva das crianças. Assim, destaca-se que o brincar influencia positivamente na recuperação da criança (RIBEIRO et al., 2002), portanto sua adoção é indispensável.

O Projeto de Extensão Aprender/Ensinar Saúde Brincando da Universidade Federal de Pelotas é desenvolvido há seis anos pela Faculdade de Enfermagem. Ao longo do seu tempo de funcionamento contou com a participação de acadêmicos dos cursos de Enfermagem, Educação Física, Farmácia, Nutrição e Odontologia. O objetivo do Projeto é realizar educação em saúde com o público infantil por meio da utilização de atividades lúdicas e do brinquedo terapêutico. O público alvo são crianças internadas nas pediatrias de dois hospitais um hospital filantrópico e um hospital escola, uma escola municipal em suas séries iniciais e um grupo de crianças portadoras de anemia falciforme.

O Projeto visa inserir os acadêmicos precocemente no Campo da Pediatria, considerando a importância da realização de atividades extracurriculares e de proporcionar uma maior interação com o público infantil, além disso, enfatiza-se também o trabalho multiprofissional, abrangendo várias áreas do cuidado em saúde. O trabalho de equipes multiprofissionais é destacado como uma forma de intervenção na qual o intercâmbio entre saberes profissionais acontece de forma produtiva e definida. Para tanto, é importante que haja troca para melhora dos relacionamentos entre a equipe, culminando na melhora da qualidade do cuidado prestado ao paciente (MINELLI; SORIANO; FÁVERO, 2009).

Através da aproximação com a utilização do brinquedo terapêutico no desenvolvimento das atividades é possível perceber que a criação do vínculo entre os participantes é facilitada, visto que por meio dessa prática há formação de confiança, devido à adequação da postura dos acadêmicos frente à criança. A criança passa a enxergar o profissional como alguém que almeja o seu bem estar e que lhe ensina formas de saber ter um desenvolvimento saudável, ou seja, há a desmitificação do profissional de saúde enquanto a pessoa que realiza os procedimentos dolorosos e, por consequência, do hospital como um lugar triste, no qual somente há sofrimento e dor. 
Observou-se que por meio do Projeto que os acadêmicos aprenderam a lidar e conversar de forma mais adequada e espontânea com as crianças, visto que as atividades e a possibilidade de ter um contato maior com o público infantil aumenta a confiança desses em relação a elas, além de favorecer uma melhora na forma de expressão no contexto geral da Universidade. Por meio das atividades de educação em saúde realizadas com as crianças, em que o uso do lúdico é central, torna-se possível a adoção de novas formas de fazer saúde, nas quais as crianças se percebem como participantes do processo, tendo voz e vez, com seus direitos reconhecidos e preservados.

\section{O PROGRAMA CRESCENDO COM UM SORRISO - NÚCLEO DE ATENÇÃO ÀS DISFUNÇÕES OROFACIAS NA CRIANÇA}

Na realidade atual, a atenção à saúde bucal dirigida às crianças está em sua maioria infelizmente voltada para os problemas prioritários, como o tratamento de cáries e outras infecções. Entretanto, uma parte significativa desse público apresenta outros problemas de saúde importantes, como é o caso das disfunções orofaciais e problemas de crescimento e desenvolvimento associados. Esses problemas podem ser grandemente deletérios ao desenvolvimento da oclusão dentária, comprometer o crescimento facial, a saúde geral e a qualidade de vida das crianças. A abordagem de problemas orofaciais crônicos de natureza funcional requer muitas vezes equipes multidisciplinares bem articuladas, além da participação de profissionais dispostos a enfrentar desafios constantes e esforço continuado.

Neste contexto se insere o Programa Crescendo com um Sorriso, iniciativa do Núcleo de Atenção as Disfunções Orofaciais nas Crianças (NADOC-UFPel), estruturado em 2015 pelo estímulo e financiamento nos editais ProExt do Ministério da Educação (MEC), além do apoio continuado da Pró-Reitoria de Extensão e Cultura da UFPel. O programa envolve três projetos de extensão articulados, que desenvolvem ações preventivas e educativas em escolas e outros ambientes de saúde, além de assistência à pacientes infantis com desordens funcionais crônicas e hábitos orais deletérios no âmbito da Ortodontia.O público alvo principal do programa são crianças, em idade pré-escolar e escolar, de escolas públicas do município de Pelotas e que recebem atenção regular em saúde na clínica infantil da Faculdade de Odontologia da UFPel, além dos seus responsáveis. $\mathrm{O}$ programa envolve atualmenteseis docentes, das áreas de Ortodontia, Odontopediatria, Radiologia e Oclusão, trinta e quatro alunos de graduação, dois alunos de pós-graduação em Odontologia e um Técnico Administrativo em Educação. As atividades são desenvolvidas na Faculdade de Odontologia, hospitais e em nove Escolas públicas da ci- 
dade de Pelotas, atingido mais de 2500 crianças/ano. O programa busca atualmente conexão com outros projetos e inserção nos serviços públicos de saúde, a fim de ampliar a sua abrangência, realizar troca de experiências e melhorar a qualidade de suas ações. A sua orientação essencial está alicerçada nos reforços dos elos entre a universidade e a sociedade, ao mesmo tempo que busca promover nos discentes participantes o senso ético e social baseado na humanização da saúde e na aspiração ao melhoramento contínuo.

\section{CONSIDERAÇÕES FINAIS}

A análise do tema saúde da criança como direito fundamental, sob a perspectiva histórica dos conceitos sociais e das políticas públicas que construíram esse sentido de direito até o presente, pode oferecer um importante substrato para as discussões a respeito da Universidade como instrumento de crescimento da sociedade. Esse exercício requer também o olhar para os sujeitos e para o modo de organização da Extensão Universitária, e em última análise dos próprios Serviços de Saúde a ela vinculados. Assim, é muito importante que extensionistas que trabalham com saúde possam deliberadamente participar de todas as iniciativas que venham a trazer o encontro de confluências, a associação de diretrizes e políticas de trabalho, de práticas multiprofissionais, e especialmente que favoreçam ao crescimento do aprender o fazer em conjunto. Esses princípios podem seguramente alavancar a promoção da saúde e a qualidade de vida de crianças e suas famílias em trabalhos de extensão. O empenho coletivo na construção de parcerias, assim como o compartilhamento de práticas, para além da comunidade com a qual estudantes e professores possam estar envolvidos, poderá possibilitar o exercício de uma extensão mais forte e mais ampla. Essas estratégias certamente podem acentuar ainda mais o já importante papel da Universidade como agente de transformação social. Nesse contexto, cabe salientar que ao acadêmico cabe assumir sempre um posicionamento que lhe permita ser agente público imbuído de observação, crítica e espírito de intervenção, sendo, portanto, capaz de contribuir para a construção continuada do respeito, da proteção e da efetivação dos direitos humanos.

REFERÊNCIAS

ALMA-ATA (URSS). Conferência Internacional sobre cuidados primários de saúde. Disponível em: <http://cmdss2011.org/site/wp-content/uploads/2011/07/Declara\%C3\%A7\%C3\%A3o-Alma-Ata.pdf>. Acesso em: 3 abr. 2017.

BRASIL. Decreto ํㅜ 6.286, de 5 de dezembro de 2007. Institui o Pro- 
grama Saúde na Escola - PSE, e dá outras providências. Diário Oficial da União, Brasília, 5 dez. 2007. Disponível em: <http://www.planalto.gov.br/ ccivil_03/_ato2007-2010/2007/decreto/d6286.htm>. Acesso em: 15 mar. 2017.

BRASIL. Lei no 13.105, de 16 de março de 2015. Código de Processo Civil. Diário Oficial da União, Brasília, 16 mar. 2015. Disponível em: <http://www.planalto.gov.br/ccivil_03/_Ato20152018/2015/Lei/L13105.htm\#art1048ii>. Acesso em: 15 mar. 2017.

BRASIL. Lei no 8.069, de 13 de julho de 1990. Dispõe sobre o Estatuto da Criança e do Adolescente e dá outras providências.Diário Oficial da União, Brasília,13 jul. 1990. Disponível em: <http://www.planalto.gov.br/ ccivil_03/leis/l8069.htm>. Acesso em: 15 mar. 2017.

BRASIL. Lei $n^{\circ}$ 8.242, de 12 de outubro de 1991. Cria o Conselho Nacional dos Direitos da Criança e do Adolescente (Conanda) e dá outras providências.Diário Oficial da União, Brasília, 12 out.1991. Disponível em: <http:// www.planalto.gov.br/ccivil_03/leis/L8242.htm>. Acesso em: 15 mar. 2017.

BRASIL. Ministério Da Saúde. Assistência integral à saúde da criança: açõesbásicas.Brasília: Ministério da Saúde, 1984.

Declaração dos direitos da criança. Disponível em: <http://www. direitoshumanos.usp.br/index.php/Crian\%C3\%A7a/declaracao dos-direitos-da-crianca.html>. Acesso em: 15 mar. 2017.

Saúde, 2016b.

Estatuto da criança e do adolescente. Brasília: Ministério da

Saúde da família: uma estratégia para a reorientação do modelo assistencial. 2. ed.Brasília: Ministério da Saúde, 1998.

Saúde da criança: acompanhamento do crescimento e desenvolvimento infantil. Cadernos de AtençãoBásica, Brasília, n.11, 2002. Série A. Normas e Manuais Técnicos.

Agenda de compromissos para a saúde integral da criança e redução da mortalidade infantil.Brasília: Ministério da Saúde, 2004.

FIGUEIREDO, G.L.A.; MELLO, D.F. Atenção à saúde da criança no Brasil: aspectosda vulnerabilidade programática e dos direitos humanos. Revista Latinoamericana de Enfermagem, v.15, n.6, 2007.

FUNDAÇÃO OSWALDO CRUZ. Saúde: um direito fundamental. Radis-Comunicação em Saúde, v. 5, n.13, p. 16-18, 2003. 
MARCÍLIO, M. L. A criança abandonada na história de Portugal e do Brasil. In: VENÂNCIO, R. P. (org.). Uma história social do abandono no Brasil. São Paulo: Alameda; Ed. PUC Minas; Cortez, 2010.p. 13-37.

MELLO, D.F. et al.Seguimento da saúde da criança e a longitudinalidade do cuidado. Revista Brasileira de Enfermagem, v. 65, n.4, p. 675679, 2012.

MONTEIRO C.A.; FREITAS, I.C.M. Evolução de condicionantes socioeconômicas da saúde na infância na cidade de São Paulo (1984-1996). Revista de SaúdePública, v.34, n.6, p. 8-12, 2002.

ORGANIZAÇÃO DAS NAÇÕES UNIDAS. Declaração universal dos direitos das crianças, 1959. Disponível em: Disponível em[T1]: <http://www. dhnet.org.br/direitos/sip/onu/c_a/lex41.htm>. Acesso em: 25 mar. 2017.

ORGANIZAÇÃO PAN-AMERICANA DA SAÚDE.Organização Mundial da Saúde. Melhorando a saúde das crianças. ICPCD: o enfoque integrado. Brasília: OPAS/ICPCD, 2000.

RIBEIRO, C. A. et al. Mesa-redonda: o brinquedo e a assistência de enfermagem à criança. Enfermagem Atual, v. 2, p. 6-17, 2002.

RIO GRANDE DO SUL. Ministério Público do Estado. Direitos humanos de crianças e adolescentes.Disponível em: <https://www.mprs.mp.br/infancia/doutrina/id455.htm>. Acesso em: 25 mar. 2017.

RIZZINI, I. O século perdido:raízes históricas das políticas públicas para infância no Brasil. 3. ed. São Paulo: Cortez, 2011.

RIZZINI, I;RIZZINI, I. A institucionalização de crianças no Brasil: percurso histórico e desafios do presente. 2. ed. Rio de Janeiro: Ed. PUC-Rio; São Paulo: Loyola, 2004.

SANTOS, M.P. et al. Direitos humanos e Estatuto da Criança e do Adolescente: estudo de caso em uma ONG no Rio de Janeiro/BR. Disponível em:<http://www.lapeade.com.br>. Acesso em: 28 mar. 2017.

SCHUCH, P. Direitos e sensibilidades: uma etnografia das práticas de justiça da infância e juventude. In: GROSSI, M. P.; HEILBORN, M. L.; MACHADO, L. Z (orgs.). Antropologia e direitos humanos.4. ed. Blumenau: Nova Letra, 2006. p.57-120.

UNICEF. World declaration on the survival, protection and development of children. New York, 1990. 
gestante e do bebê. São Paulo: Globo; 2011.

Fundo das Nações Unidas para a Infância. Declaração dos Direitos das Crianças. Disponível em: <https://www.unicef.org/brazil/pt/resources_10120.htm>. Acesso em: 3 abr. de 2017.

VIANNA, A. R. B. Limites da menoridade: tutela, família e autoridade em julgamento. Tese Museu Nacional/UFRJ. Rio de Janeiro: PPGAS/Museu Nacional; UFRJ, 2002.

VICTORA, C.et al. Saúde de mães e crianças no Brasil: progressos e desafios. Lancet, v. 377, n. 9780, p. 1863-1876, 2011.

Figura 1

Membros da equipe do

Projeto de Extensão

Aprender/Ensinar Saúde

Brincando, coordenado pela

prof ${ }^{a}$. Dra. Ruth Irmgard

Bärtschi Gabatz do curso de

Enfermagem na UFPel.

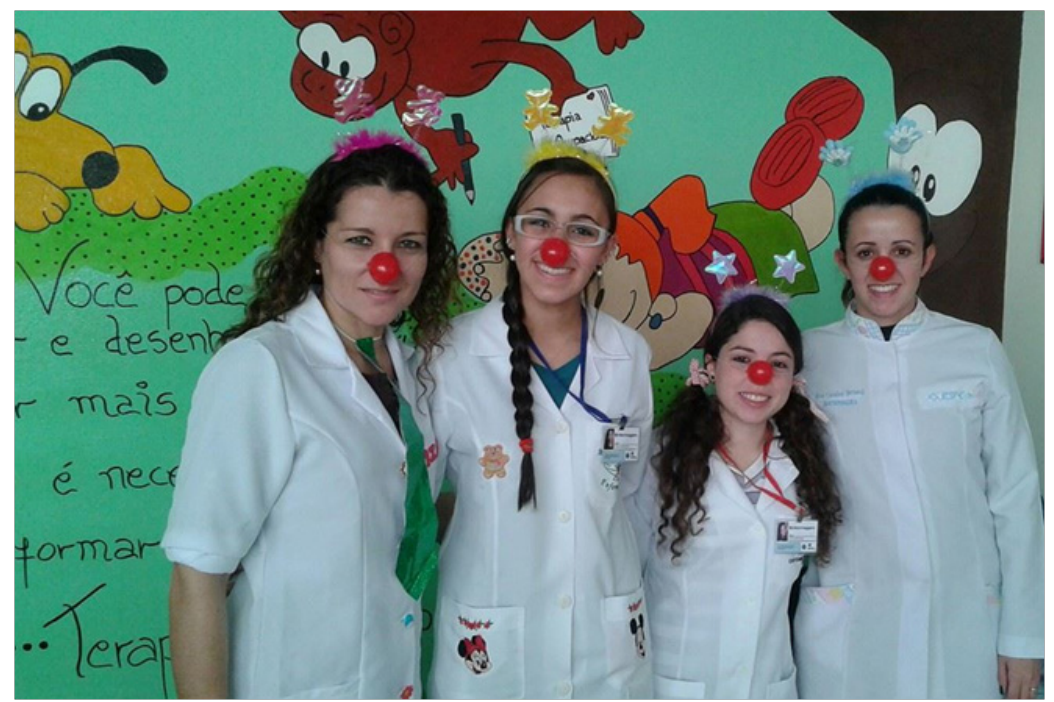

Fonte: Autores.

Figura 2 Membros da equipe

Programa de Extensão Crescendo com um Sorriso -

Núcleo de Atenção às

Disfunções Orofaciais na

Criança, coordenado pelo prof. Dr. Douver Michelon do curso de Odontologia na UPFel.

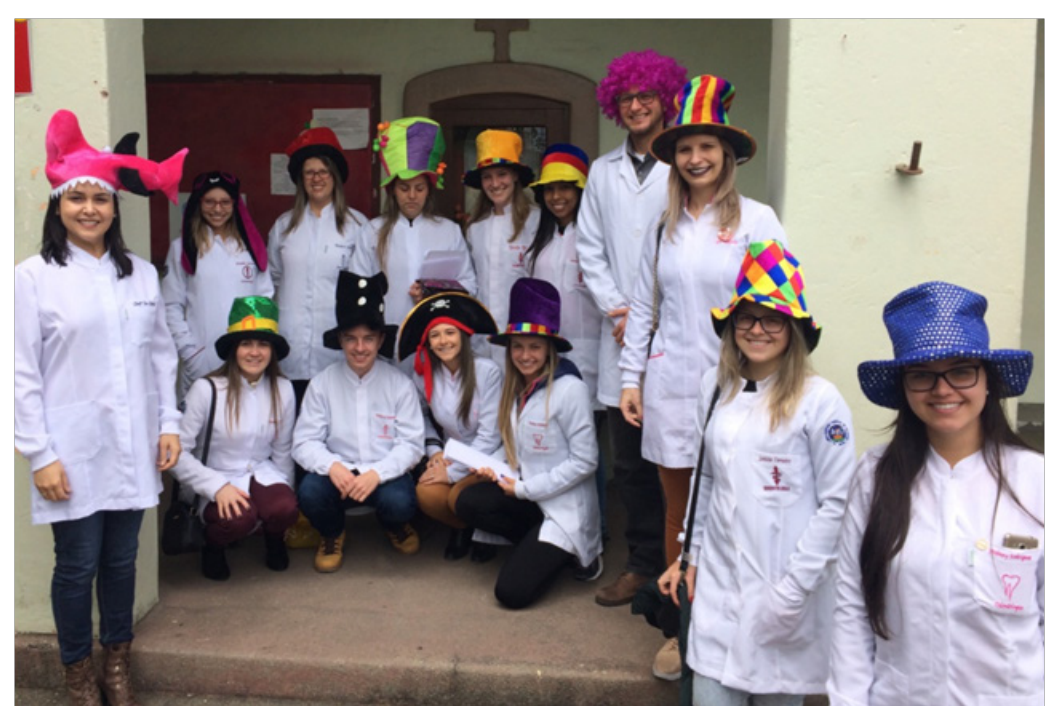

Fonte: Autores. 


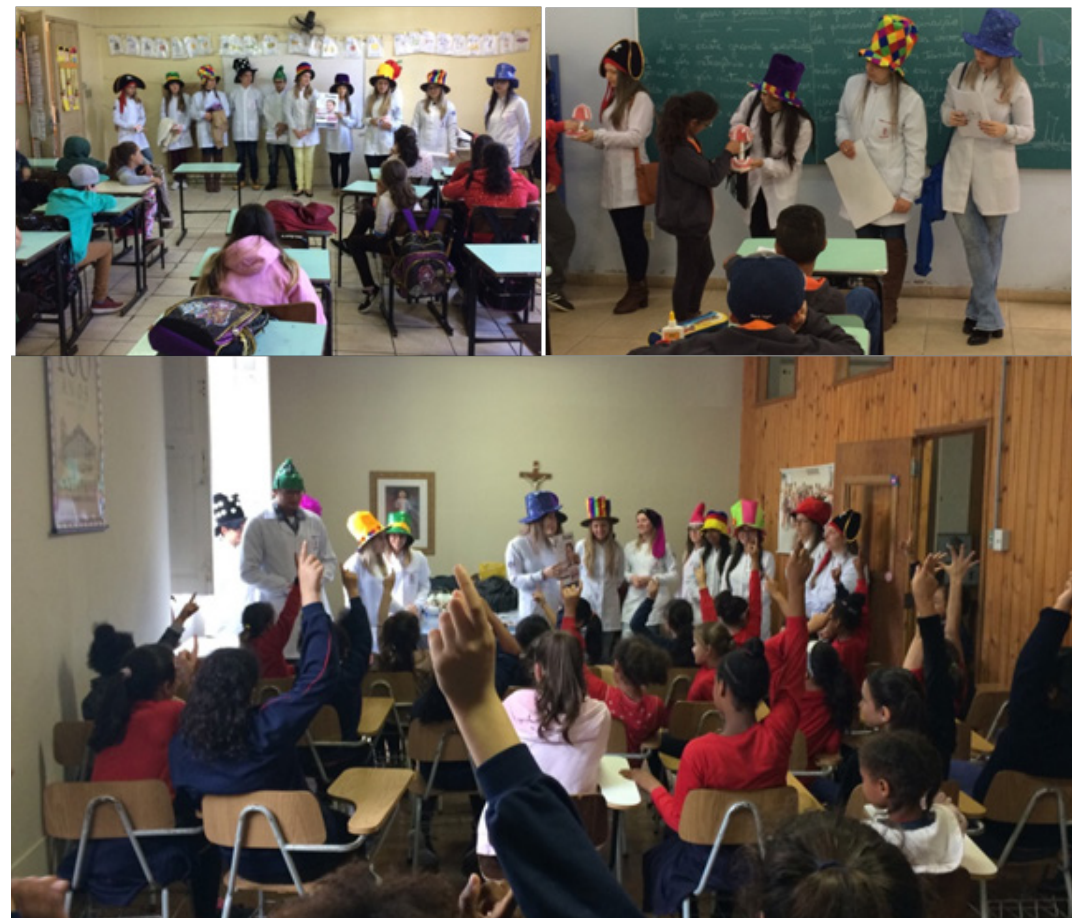

Fonte: Autores.

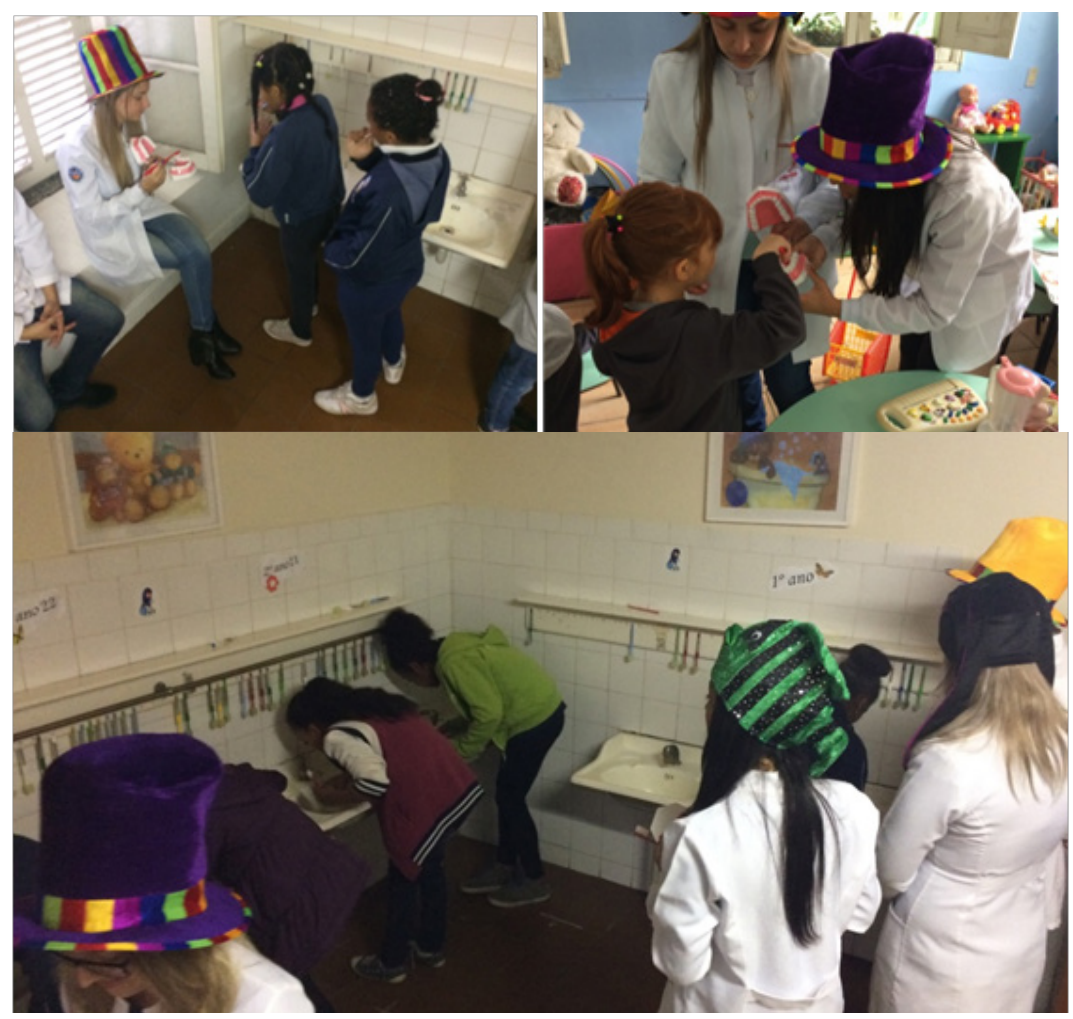

Fonte: Autores.
Figura 3

Atividades nas Escolas com finalidade educativa e preventiva, baseadas no estímulo e na promoção de comportamentos e hábitos favoráveis a saúde em instituições.

\section{Figura 4}

Escolares recebendo orientações de membros das equipes sobre práticas em higiene pessoal durante atividade de extensão nas instituições parceiras.

Data de recebimento: 17 de abril de 2017 .

Data de aceite para publicação: 21 de junho de 2017 . 